was never any sriell noticed: At the commencement : of 1876 , he attended.St. Mary's Haspital, and for some :months was given iodide of potassium, as he trad contracted a chancre fifteen years previously. He had never since the : sore been ' affected with inyrisecondary symptoms. This treatment gave him no relief. In the eariy part of the winter of

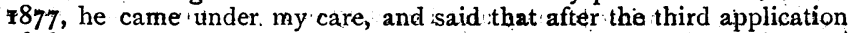
of the spray he began to feel better. The spray was continued: for over two months, the patient attending two or three times a week, no interrial remedies being given. Since'then there has been no return of the discharge, or any recurrence of the attacks of sneezing.

REMARKS. - These cases are, with one exception, all typical cases of simple ozæna. They presented most of the common symptoms of the complaint, which are : congestion of the mucous membrane with, commonly, slight thickening ; crustations of :dried mucus blocking up the'nostrils, which, on being removed, discover ulceration of the mucous surface, and occasionally destruction of bone; a constant discharge, either scanty or copious, thin or thick; perhaps mixed with blood, and frequently so offensive that : the i sufferer is debarred from society; a ranning of the discharge, when the patient is lying down, into the tarynx. In two cases in which the patients have suffered from chronic laryngitis previous to incurring ozena, the irritation caused by this gravitation of the nasal discharge has materially helped, it would seenr; to keep up the laryngeal congestion. Pain in or about the nostrils, or a feeling of discomfort, isevere enongh to keep the patient awake at night; redness of the skin over the bridge of the nose; the eyes or eyesight are in some cases affected. During the catamenial period the symptoms are with many increased. This ozenic condition causes a great depression of spirits, and with some patients a disgust for life, insomuch that they have often confessed to feeling inclined to commit suicide, and thus free themselves from what seemed to be an incurable disease.

I have inserted one syphilitic case, for the sprays appear to assist the constitutional remedies. This has been made evident in the case of a gentleman who came to me for ulceration in the right nostril, the result of primary disease contracted ten years :ago... It seems to me that in these cases of specific disease it is better to employ mercury rather than iodide of potassium, on account of the common tendency of the latter trug to cause a nasal discharge, at any rate to give it as isparingly as possible. A clergyman, who was under my care last year, after he had been cured of ozena took iodide of potassium for sciatica. At the end of a fortnight he had all his ozænic troubles back, and as they did not leave him after remission of the drug he was obliged to return for the spray-treatment.

\section{A NEW ANTISEPTIC DRESSING.}

\section{By HERBERT L. SNOW, M.D.Lond., Bayswater.}

IN the Journal for February 28 th, occurs a memorandum by SurgeonMajor MacNamara, in which the question is asked, "What is the best stłostitute in military surgery for exact antiseptic dressing?" And lint, soaked in carbolic acid solution, then covered by a layer of cottonwool, is the substitute proposed. I. venture to suggest another, which I think will be found far superior to this, and which is, indeed, in some respects better than the ordinary Listerian applications for ordinary hospitat practice. The dressing to which I allude is called "antiseptic marine lint"; the packages I have seen bear the name of $T$. Westhorp, Falcon Worlts, West India Road, E. It is practically fine oakum, but differs from the tenax in ordinary: surgical use in being more oily, more tenacious, and more thoroughly saturated (to all appearance) with tarry principles.

My experience of it extends to nine or ten operation-cases, chiefly excisions of the breast. I have operated on those under the carbolic spray; have subsequently applied a layer of the "marine lint", moistened with carbolic solution (without any intervening protective), and two or three 'dry layers of the same over this; outside the whole, a piece of mackin. tosh and ordinary calico bandages. The cases were dressed again (always under the spray) on the third day; subsequently, at intervals of from five days to a week. All except one united without any suppuration, quite as cleanly and as rapidly as under the complete Listerian plan. In the exception (a case of excision of the breast for cancer), torsion had been used instead of the ordinary catgut ligatures; there was consequently a profuse serous oozing reaching the outer atmo'sphere; the mackintosh and amount of "marine lint" were not proportionately enlarged; and the method accordingly failed in preventing supparation, though subsequently good recovery took place.

For ordinary hospital purposes, this "'marine lint" has two advan tages over the Listerian gauze; the first is, that it acts much more completely as a sponge, soaking up and holding innocuous in its meshes a
Jarge quantity of discharge; the second, that it is very much cheaperthe expense being $2 \mathrm{~d}$. or $3 \mathrm{~d}$. per dressing, in comparison with from 1.8. 6d, to $2 \mathrm{~s}$. $6 \mathrm{~d}$, in the other case.

For military surgery, $I$ am confident that it will prove the best ready application hitherto devised. The sponge-like action is very valuable and, when applied on the battle-field to wounds, the large amount of tarry principle held in solution is amply sufficient to keep a wound aseptic for several days, even without the useful adjunct of carbolic solution to moisten the first dressings.

My experience of cotton-wool as a dressing for operation-cases is decidedly unfavourable. It filters the air, doubtless; but in practice the surface next the wound becomes "caked" by the discharge ; an impervious "skin" thus formed pens up the latter, and" frequent dressings are necessary, or bad consequences quickly follow.

In a dangerous and critical operation, it is a good plan to use Lister's method in its entirety for the first two or three dressings; subsequently, when the discharge has lessened, the "marine lint". I need hardly point out the advantages of this latter as a dressing for large burns in the suppurating stage, or as an application to foetid cancerous ulcers, etc.

So far, I am not disposed to trust this absorbent lint quite so implicitly as the carbolic gauze and protective; but it is far. cheaper, less complicated, and readier of application, and in the majority of ordinary operation-cases answers quite as well.

\section{ATTEMPTED SUICIDE BY STRYCHNIA, SUCCESS- FULLY TREATED BY HYDRATE OF CHLORAL.*}

\section{By GEORGE GRAY, M.D., Castlewellan, Co. Down.}

ON December 3oth, 1879, I was called upon to visit a man living about two miles and a half distant, who, the messenger informed me, had taken a poisonous dose of strychnia. When $I$ arrived at the house, about half-past twelve o'clock, I found the patient; a man 34 or 35 years of age, supported in bed in a semirecumbent position, with his head thrown back, his eyes staring, and evidently suffering from the usual symptoms of poisoning by strychnia. The muscular spasm came on with a tremor like a jerky kind of convulsion, and recurred about every three minutes. During the spasm, the breathing was irregular, and the breath came through the closely clenched teeth with a hissing sound. The angles of the mouth were drawn down, and the peculiar Sardonic grin well marked; the skin was cold, and covered with a clammy perspiration. The pulse was very weak and quick, but not irregular. During the intervals between the convulsive attacks, the spasm of the jaw did not pass off, and any attempt to open the mouth forcibly at once brought on a fresh attack, which was preceded by a peculiar sound -half groan, half cry.

Having brought with me a solution of two drachms of hydrate of chloral in two ounces of water, I poured half of it into a cup, and managed slowly to administer it with a teaspoon by inserting the point of the latter in a space where he had lost two molar teeth, and directing him to suck in the fluid. This he did in the intervals of the attacks, swallowing it with a gulp until the ounce of fluid was taken. After swallowing the chloral, he had only two severe spasms, the latter less marked than the former; and, at gradually lengthening intervals, they became less severe. In ten minutes, the jaw was so relaxed that I thought I could introduce the tube of a stomach-pump, but as doing so seemed to cause great distress and increased the jerking of the muscles, I did not persevere, but gave him an emetic of thirty grains of sulphate of zinc and warm water, and when this had acted I gave him a drachm of tannin; this he vomited also.

After waiting for an hout, as there were now and then slight tremors in some of the muscles, as no doubt some of the chloral was removed by the emetic, and as there was not any drowsiness, I gave half what remained of the solution - that is, half a drachm of chloral-hydrate, and applied warmth to the skin. In another hour, he was so much improved that I left, giving directions that if he had any more twritching, or if he had not any drowsiness - which had not yet appeared-to give him in three hours the remainder of the draught, and to let: me hear of him in the evening. At seven o'clock, I heard that he had the chloral draught at five, but had not slept, and was feeling comfortable, having no more vomiting or convulsions. I ordered him a dose of castor-oil at bedtime.

There is nothing further to note of the progress of the case, as, two days afterwards, he was at his usual work.

On making inquiry, I found that, for a fortnight before, he had

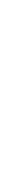

.

.

